\title{
e-Migrinter
}

6 | 2010

Rroms \& Gens du Voyage

\section{Anaïk Pian, Aux nouvelles frontières de l'Europe. L'aventure incertaine des Sénégalais au Maroc}

\section{Gunhild Odden}

\section{(2) OpenEdition}

Journals

Édition électronique

URL : https://journals.openedition.org/e-migrinter/993

DOI : 10.4000/e-migrinter.993

ISSN : 1961-9685

Éditeur

UMR 7301 - Migrinter

\section{Édition imprimée}

Date de publication : 15 octobre 2010

Pagination : 98-99

ISSN : 1961-9685

\section{Référence électronique}

Gunhild Odden, «Anaïk Pian, Aux nouvelles frontières de l'Europe. L'aventure incertaine des Sénégalais au Maroc », e-Migrinter [En ligne], 6 | 2010, mis en ligne le 07 juin 2018, consulté le 20 mai 2021. URL :

http://journals.openedition.org/e-migrinter/993 ; DOI : https://doi.org/10.4000/e-migrinter.993 


\section{Anailk Pian (2009) Aux nouvelles frontières de l'Europe. L'aventure incertaine des Sénégalais au Maroc, Paris, La Dispute, 237 p.}

Gunhild Odden

$\mathbf{L}$ 'ouvrage d'Anaik Pian nous propose de mettre en perspective la confrontation entre deux logiques: celle des politiques migratoires et celle de l'aventure migratoire. À partir d'un travail de terrain ethnographique approfondi, réalisé au Maroc entre 2003 et 2006, Pian nous fournit ici des données empiriques riches et originales, donnant un visage autre des migrants subsahariens qui tentent d'atteindre la rive Nord de la Méditerranée. Si l'accent est mis sur les migrants sénégalais, représentant l'un des premiers groupes de migrants subsahariens en transit au Maroc, les autres nationalités ne sont pas pour autant omises. Congolais, Camerounais, Nigérians ou autres sont fréquemment mentionnés, tout comme les Marocains d'ailleurs, révélant ainsi des modes d'organisation similaires ou distincts, coopératifs ou compétitifs. Un des mérites de cette étude sur les Sénégalais est ne pas s'être limitée aux seuls Sénégalais.

Deux parties structurent la démonstration. Une première porte sur les parcours migratoires des aventuriers sénégalais. L'auteur nous dévoile ici le profil de ces migrants, leurs motivations à voyager et leur état d'esprit au moment de quitter le Sénégal, soit des éléments qui rompent avec la vision misérable des représentations communes de ces migrants. À partir des récits des migrants, Pian évoque le périple jusqu'au Maroc, les lieux d'attente forcée une fois que l'on y arrive et les stratégies mises en œuvre afin d'atteindre l'Europe - telles la traversée maritime, l'entrée par les enclaves espagnoles ou le recours aux faux-papiers - et, surtout, comment le parcours se construit et se redéfinit au gré des rencontres, opportunités et contraintes : avec un passage vers l'Europe de plus en plus difficile, des contrôles migratoires de plus en plus stricts, le périple est marqué par de nombreux détours et retours en arrière.

La deuxième partie de l'ouvrage traite plus spécifiquement de la situation des aventuriers au Maroc, cet « entre-deux » dans lequel se retrouvent prisonniers nombre d'aventuriers lorsque, au fil des mois ou des années, leur chance de parvenir en Europe apparaît comme compromise (p. 26). Deux systèmes d'organisation sociale sont décrits: «les foyers » sénégalais à Rabat et le campement informel de Bel Yones, forêt située à proximité de l'enclave espagnole de Ceuta.

L'expérience d'une mobilité bloquée en cours de route devient alors centrale dans cette deuxième partie. Conscients que le passage se présente comme difficile, voire impossible, Pian montre comment certains trouvent des alternatives au retour: l'insertion dans les réseaux sénégalais de commerce à la valise à Casablanca, soit une logique s'inscrivant dans une longue tradition.

Plus qu'une simple présentation des parcours des migrants et de la situation de transit au Maroc, Pian nous dévoile des mécanismes sociaux que seule une démarche ethnographique s'inscrivant dans la durée puisse fournir. La richesse de la méthode empirique choisie se reflète également dans le style de l'écriture: la description de la petite lucarne qui donne sur les toits du 
quartier de Takadoum à Rabat, ou celle des cordes à linge qui avoisinent les antennes paraboliques, ne se présente pas comme superflue, mais invite le lecteur à se plonger dans le décor, à vivre - du moins littéralement - de l'intérieur l'aventure des aventuriers. Le terme d'aventurier est d'ailleurs précisé dans l'introduction où l'auteur rappelle son histoire et explique l'utilisation qu'elle en fait.

Tout au long du livre, Pian fait référence à un grand nombre d'auteurs, classiques ou plus récents, ce qui permet une mise en perspective du contexte marocain d'une part, et un apport bibliographique d'autre part. On apprécie les quelques mises à jour datant d'un terrain ultérieur (2008).
Enfin, le contexte migratoire au Maroc, mais aussi celui en Europe, ayant beaucoup changé depuis la période principale de l'enquête (2003-2006), on se demande ce qu'il en est actuellement de la situation de Mustapha, Justin, Fatou et les autres, ou encore de celle dans les foyers ou dans les campements informels. Seule une suite pourrait nous le dire.

Gunhild Odden Doctorante à MIGRINTER Chercheure au Centre pour la communication interculturelle (SIK), Stavanger, Norvège 